Review Article

\title{
Clinical Spectrum of Complications Induced by Intravesical Immunotherapy of Bacillus Calmette-Guérin for Bladder Cancer
}

\author{
Yuqing Liu (D), Jian Lu (D), Yi Huang, and Lulin Ma \\ Urology Department, Peking University Third Hospital, Beijing, China \\ Correspondence should be addressed to Jian Lu; lujian@bjmu.edu.cn
}

Received 27 August 2018; Revised 24 January 2019; Accepted 12 February 2019; Published 10 March 2019

Academic Editor: Reza Izadpanah

Copyright ( 2019 Yuqing Liu et al. This is an open access article distributed under the Creative Commons Attribution License, which permits unrestricted use, distribution, and reproduction in any medium, provided the original work is properly cited.

\begin{abstract}
Because of its proven efficacy, intravesical Bacillus Calmette-Guérin (BCG) immunotherapy is an important treatment for nonmuscle invasive bladder cancer at high risk of recurrence or progression. However, approximately $8 \%$ of patients have to stop BCG instillation as a result of its complications. Complications induced by BCG therapy can have a variety of clinical manifestations. These adverse reactions may occur in conjunction with BCG instillation or may not develop until months or years after BCG cessation. An essential step in the management complications arising from BCG is early establishment of diagnosis, particularly for distant, disseminated, and obscure infections. Therefore we reviewed the literature on the potential complications after intravesical BCG immunotherapy for bladder cancer and provide an overview on the incidence, diagnosis, and treatment modality of genitourinary and systemic BCG-induced complications.
\end{abstract}

\section{Introduction}

Bladder cancer is the ninth most commonly diagnosed cancer and the thirteenth leading cause of cancer deaths worldwide, with an estimated 429,000 new cases and 165,000 deaths worldwide in 2012 [1]. The majority of patients diagnosed with bladder cancer present with nonmuscle invasive bladder cancer (NMIBC), including carcinoma in situ (CIS) and $\mathrm{Ta}$ and $\mathrm{T} 1$ stage. Although the gold standard management for NMIBC is complete removal of all papillary lesions via transurethral resection (TUR), there is a high rate of recurrence after the initial surgery. For all high grade and some low grade NMIBC, intravesical immunotherapy of bacillus Calmette-Guérin (BCG) is the one recommended in all the guidelines [2]. The meta-analyses of randomized trials have shown that intravesical maintenance BCG after TUR reduced the recurrence rates significantly [3], and BCG significantly reduces the risk of progression to muscle invasive disease after TUR in patients who receive maintenance BCG [4].

Despite the fact that adjuvant intravesical BCG immunotherapy is significantly more active than surgery alone, a retrospective chart review showed that only $50 \%$ of high-risk patients of NMIBC received BCG maintenance therapy as recommended by the EAU and AUA guidelines [5].
The substantial occurrence of complications was regarded as one of the main reasons for poor compliance to BCG therapy. Besides this, it was reported that only $16 \%$ of patients on maintenance BCG were able to receive all instillations of the 3-year immunotherapy, mainly because of adverse events [6]. In a more recent report on European Organization for Research and Treatment of Cancer (EORTC) trial 30911, 19\% of patients who accepted intravesical BCG had to stop the treatment because of complications, and $29 \%$ completed the 3-year immunotherapy [7].

Since the precise immunological mechanism of BCG therapy is still unclear, the pathogeneses of adverse reactions following intravesical BCG instillation have been not fully explained. A controversy exists between the inflammatory hypersensitivity hypothesis, supported by histological findings of granulomas in the absence of microorganisms, and the bacteria invasion hypothesis based on the reports about the positive finding of active bacilli in a variety of tissues. [8] The first essential step following BCG instillation is attachment of live BCG to the urothelium, which brings about recruitment of immune cells to the area, initially granulocytes, followed by macrophages and lymphocytes, and the urinary release of cytokines, which is more pronounced in the case of BCG exposure, reflecting recall immune activation [9]. However, 
from another point of view, the microbiological identification of Mycobacterium bovis (M. bovis) from cases of focal disease sites and the fact that ofloxacin administration following intravesical BCG significantly reduced the incidence of BCG-related complications favor argument for direct and hematogenous BCG invasion and infection [10].

Complications induced by BCG can occur and may vary from self-limited irritative voiding symptoms to severe systemic sepsis. According to the results of the largest and most recent published study by the EORTC GenitoUrinary Cancers Group, of the 1316 patients who started BCG, $69.5 \%$ reported with local (62.8\%) or systemic (30.6\%) complications [11]. Chemical cystitis (35.0\%) and general malaise $(15.5 \%)$ were most frequent, and a total of 103 patients (7.8\%) stopped treatment because of complications. From a case series and literature review, 282 cases of BCG infection after intravesical instillation were analyzed, and the most common presentations included disseminated (34.4\%), genitourinary (23.4\%), and osteomuscular (19.9\%) infections [8]. The reported incidence of complications induced by intravesical BCG therapy was listed in Table 1.

There are some difficulties in diagnosis of the complications induced by BCG immunotherapy, especially of severe ones. Many complications occur late up to years after cessation of BCG therapy, and symptoms may involve elsewhere beyond the lower urinary tract. Even if there are obvious alarm symptoms induced by BCG, it may be difficult to prove the suspected BCG-related complications. Acid-fast bacilli staining, mycobacterial culture, and polymerase chain reaction (PCR) testing are often negative. Frequently, tissue biopsies are required to evaluate noncaseating granuloma formation, and specimen cultures are helpful to identify the presence of $M$. bovis. The overall rate of positive findings is $48 \%$ on microbiological studies (acid-fast bacilli stain, culture, and PCR assay) and $65.5 \%$ on tissue biopsy, and identification of granulomatous inflammation on specimen is available in $86.3 \%$ of cases [8]. It is a key point that the prognosis of a complication is usually dependent on early treatment initiation, so a high clinical suspicion is important to avoid delay in management. Considering the fact that most complications occur when the patient is already at home, it is quite important that primary care doctors be informed that the patient has received intravesical BCG and be familiar with possible adverse events of BCG, alarming symptoms, and practical knowledge on how to deal with the problems.

In this review, we summarized updated clinical studies and illustrative case reports to provide an overview on the incidence, presentation, diagnosis, and treatments of potential genitourinary and systemic complications resulting from intravesical BCG immunotherapy for NMIBC.

\section{Genitourinary Complications}

2.1. Cystitis. Irritative lower urinary tract symptoms are the most common complication after intravesical BCG instillation [12]. Typically, these voiding symptoms can be accompanied by gross hematuria with absence of positive urine cultures. In the EORTC study with BCG instillation, 23.6\% cases suffered frequency of more than once per hour, and
$22.6 \%$ cases complained with macroscopic hematuria [11]. Urine and blood cultures are necessary to exclude bacterial urinary tract infection and/or sepsis.

If the symptoms are considered as the consequence of immune stimulation and the associated inflammatory response, usually accompanied with flu-like illness, spontaneous recovery is expected within 48 hours without intervention [13]. When these symptoms last for a longer time or become increasingly intolerable, symptomatic treatment with spasmolytics, anticholinergics, or nonsteroidal antiinflammatory drugs is empirically advised. It should be noted that no randomized clinical trials on these drugs even with extended release formulas versus placebo have ever been conducted with the exception of oxybutynin which failed to be proven effective [14].

If bacterial cystitis is diagnosed, antibiotics administration is recommended. Ofloxacin had been proved to diminish BCG-related local complications by a randomized, doubleblind clinical trial [15]. Considering the rather high risk of associated bacterial cystitis in persisting voiding symptoms, in a pragmatic way, the antibiotics therapy could start with ofloxacin blindly and then be adjusted when the result of the urine culture is available [16]. Further BCG intravesical therapy should be withheld, not only because BCG microorganisms can be sensitive to antibiotic therapy, but also for avoiding severe inflammatory reactions induced by combination of BCG-induced response and bacterial cystitis. Therefore, BCG instillation should be postponed until completion of a course of culture specific antibiotics. There is little literature to suggest that BCG efficacy is compromised by such adjustments.

2.2. Bladder Contracture. Bladder contracture induced by BCG is an uncommon but severe complication [17]. Decreased bladder capacity significantly worsens patients' quality of life and makes patients unable to tolerate BCG instillation. Although published cases of bladder contractures were observed primarily in patients in a maintenance intravesical BCG immunotherapy, there were also cases as early as in the induction phase [18]. Since all patients undergo TUR before BCG therapy, it is difficult to ascertain that BCG alone is the specific cause of bladder contractures [19]. Bladder hydrodistension was reported as an effective treatment option in patients with severely decreased bladder capacity after BCG treatment [20], and the median bladder capacity of five male and one female patients increased from $40 \mathrm{ml}$ (range 30-100 ml) to $200 \mathrm{ml}$ (175-250 $\mathrm{ml}$ ) within 2 weeks following bladder hydrodistension, with stable volumes during a median follow-up period of 32 months. However, if patients with incapacitating symptoms are refractory to conservative treatment, a short 2-4-week course of oral steroids sandwiched during anti-tuberculous therapy should be considered [21]. It is only the exceptional case that major surgery such as bladder augmentation or cystectomy is required [22].

2.3. Bladder Ulcerations. Persisting BCG infections with large inflammatory lesions in bladder can represent 
TABLE 1: Incidence of complications induced by intravesical BCG immunotherapy for NMIBC $[6,8,11-13,17,23,26,27,34,39,52]$.

\begin{tabular}{lccc}
\hline Genitourinary complications & Incidence $(\%)$ & Systemic complications & Incidence $(\%)$ \\
\hline Cystitis & $27-95$ & Fever $\left(>38.5^{\circ} \mathrm{C}\right)$ & 2.9 \\
Bladder contracture & $<1$ & Mycotic Aneurysms & $0.7-4.6$ \\
Bladder ulceration & 1.5 & Miliary pulmonary tuberculosis & 0.4 \\
Penile lesions* & 5.9 & Granulomatous hepatitis & $0.7-5.7$ \\
Tuberculous epididymo-orchitis & 0.4 & Reactive arthritis & $0.5-5.7$ \\
Symptomatic prostatitis & 10 & Tuberculous Spondylitis & 3.5 \\
Ureteral obstruction & 0.3 & BCG sepsis & 0.4 \\
Kidney infections & $0.3-3.5$ & & \\
\hline
\end{tabular}

* Penile lesions consisted of nodules, papules, plaques, or ulcers, with or without inguinal lymph node enlargement.

tuberculous-like ulcers. In a study of 858 patients with intravesical BCG immunotherapy, thirteen patients developed large bladder ulcerations (10 to $50 \mathrm{~mm}$ ) [23]. All these patients were male ( $1.8 \%$ of all male patients), all with high grade tumors and seven with invasion to the lamina propria ( $\mathrm{T} 1$ ) before BCG treatment. The duration from the initial BCG instillation to the discovery of a visible lesion by routine cystoscopy was 2-34 months (median 8 months). No patient had more than one ulceration or inflammatory lesion despite the fact that seven patients had undergone TURs for multifocal tumors. Urine specimens for mycobacterial culture showed eleven patients were positive, and anti-tuberculosis (anti-TB) therapy (rifampin and isoniazid) given to 8 patients for 6 months resulted in negative urine BCG cultures and resolution of the bladder lesions.

2.4. Granulomatous Balanitis. The most widely reported penile complication of BCG is granulomatous balanitis, with symptoms including penile edema, papules, and ulcers, occasionally associated with inguinal lymphadenopathies, typically presenting after multiple cycles of BCG [24]. The time interval between BCG immunotherapy and the onset of skin lesions has been variable, and it ranged from immediately after the instillation to 1 year after the last instillation [25]. The mechanism of infection has been thought to be associated to direct penis inoculation by traumatic urethral catheterization prior to BCG instillation, but the risk factors have been not confirmed. BCG associated granulomatous balanitis lesions were reported previously in 13 cases, including 5 with history of difficult catheterization during BCG instillation. Lymphadenopathy developed in 8 of 9 cases and histological changes (granulomas, necrosis, and ulcer) were reported in 10 cases with adequate information, and 7 of them demonstrated acid-fast bacilli in lymph node biopsies. All cases responded to anti-TB therapy (various combinations of isoniazid, rifampin, and ethambutol without a standard protocol) within 6 to 12 months [26].

2.5. Tuberculous Epididymo-Orchitis. Tuberculous epididymo-orchitis, referred to as "BCGitis," is a rare granulomatous infection resulting from intravesical BCG therapy [27]. It typically manifests as scrotal swelling, pain, dysuria, and fever, commonly occurs within a few weeks of BCG instillation, but may develop as late as 17 years after cessation of BCG therapy [28]. Various distinct gray scale sonographic patterns have been described, including epididymal enlargement or nodules with hypoechoic heterogeneous or homogeneous appearance [29]. Orchitis can demonstrate a miliary sonographic pattern, and multiple intratesticular hypoechoic nodules are thought to be characteristic of tuberculous orchitis [30]. Besides this, other typical findings are also possible, including hydrocele, scrotal skin swelling, intrascrotal calcifications, abscesses, and scrotal sinus formation. Tuberculous epididymo-orchitis can be diagnosed by granulomatous changes, caseous necrosis, and positive acid-fast bacilli in the biopsy specimen. If the development of epididymo-orchitis is delayed from cessation of BCG instillation, a multiplex PCR method can help to confirm whether the BCG strain is the responsible microbe over other mycobacterium species [31]. BCG-induced epididymo-orchitis is usually sensitive to anti-TB therapy, consisting of $300 \mathrm{mg}$ isoniazid and $600 \mathrm{mg}$ rifampin daily for three to six months [29]. To M. bovis infection with isoniazid resistance, the regimen includes a fluoroquinolone or an anti-TB aminoglycoside is an option [32]. If the lesion presents persistent pain, swelling, fever, and/or leukocytosis refractory to anti-TB therapy, scrotal exploration and epididymo-orchiectomy may be required.

2.6. Prostatitis. Granulomatous prostatitis is one of the most common complications in patients who underwent intravesical BCG immunotherapy, but its incidence is likely to be underestimated by the series of symptomatic cases [33]. In fact, of male patients with BCG instillation, only about $10 \%$ developed clinical prostatitis associated with discomfort. More than $40 \%$ presented with an elevated serum prostate specific antigen (PSA), and vast majority have histological evidence of BCG granulomatous prostatitis [34].

Despite of the high rate of histological evidence to granulomatous prostatitis, it is difficult to translate this rate to imaging findings due to the limits of radiological technology. In a study of 38 patients evaluated by contrast-enhanced CT scans before TUR and after BCG therapy, abnormal prostatic findings were found in 11 of patients (28.9\%), none of whom with any signs or symptoms associated with prostatitis [35]. The MRI characteristics of granulomatous prostatitis after intravesical BCG immunotherapy have not been described 
extensively and can be represented as a suspicious lesion for harboring prostate cancer [36].

Patients with clinical BCG-induced prostatitis may present with untypical symptoms or signs, including perineal pain, enlarged tender prostate, firm prostate nodules, and elevated prostate specific antigen (PSA). PSA elevation in patients with intravesical BCG is self-limited, and it typically returns to basal levels within 3 months in the absence of maintenance therapy [37]. Prostatic fluid staining for acid-fast bacilli is helpful to identify tuberculous prostatitis. There are sporadic reports of tubercular prostatic abscess as a complication of intravesical BCG immunotherapy [38]. Accompanied with surgical drainage, anti-TB administration is available in controlling the prostatic abscess.

2.7. Ureteral Obstruction. Ureteral obstruction is an uncommon complication resulting from intravesical BCG therapy [39]. In most instances, ureteral obstruction is transient and self-limiting after conclusion of BCG therapy. If symptomatic obstruction occurs in the upper urinary tract, a regimen of $300 \mathrm{mg}$ isoniazid and $600 \mathrm{mg}$ rifampin should be given for 3-6 months. Furthermore, temporary drainage is recommended for new onset hydronephrosis. Because of only a few reports on ureteral obstruction following intravesical BCG, there is no evidence for the superiority of either ureteral stenting or percutaneous nephrostomy. In an extremely uncommon case of acute anuria after BCG instillation, the complete obstruction of the vesicoureteral junction resolved spontaneously within 6 days after percutaneous nephrostomy [40].

2.8. Kidney Infections. BCG-induced renal infections have involved pyelonephritis and associated renal granulomas. A meta-analysis of 2602 patients revealed a mere $0.1 \%$ frequency of renal abscess following BCG instillation [39]. Post-intravesical BCG pyelonephritis may present with systemic symptoms, including persistent low grade fever, chills, fatigue, or weight loss. A hypovascular renal mass may be found by contrast-enhanced CT. Given the fact that post-TUR vesicoureteral reflux has been shown in up to $77 \%$ of patients with resection close to the ureteral orifice, the mechanism of renal BCG infections is more likely to be related to reflux of the intravesical BCG rather than hematogenous spread [41]. Renal biopsies can help to establish histopathological diagnosis based on epithelioid cell granulomas; however, acid-fast bacilli may not be present. While granulomas can sometimes be managed conservatively without anti-TB medications, a regimen of $300 \mathrm{mg}$ isoniazid, $600 \mathrm{mg}$ rifampin, and $1200 \mathrm{mg}$ ethambutol daily for 6 months is advised for BCG-induced pyelonephritis or granulomatous masses of the kidney. The treatment modality of genitourinary complications induced by intravesical BCG immunotherapy was listed in Table 2.

\section{Systemic Complications}

Systemic complications occur less frequently (3\%-7\%) but are usually much more severe. They include disseminated M. bovis infection ("BCG-osis"), persistent fever, or any organ involvement beyond genitourinary system. In a review of 282 cases, disseminated infection was defined to consist of sepsis with fever, hypotension, multiorgan failure and coagulopathy, miliary tuberculosis or fever associated with bone marrow and/or liver involvement and/or pulmonary symptoms, accounting for the largest proportion (34.4\%) of BCG-induced complications [8]. The mechanism of systemic complication induced by BCG therapy is still under investigation. Although the evidence of viable organisms in tissue supports the theory of systemic spread and dissemination of Mycobacterium spp., it has also been postulated that the systemic response is due to a systemic type IV hypersensitivity reaction to BCG [42]. Diagnosis of disseminated infection is a challenging task due to the diverse array of problems and the lack of evidence from organisms and requires a high index of clinical suspicion on the role of BCG in development of any condition. In fact, the most important clinical clue usually comes from a detailed medical history that elicits prior intravesical BCG therapy.

Clinically, an increased temperature higher than $38.5^{\circ} \mathrm{C}$ after BCG instillation should arouse a suspicion of disseminated infection, and further intravesical BCG should be withheld. Blood tests often reveal leukopenia and abnormal liver function tests, and chest X-ray may show infiltrates in the lower lung bases [43]. According to EAU guidelines on management for BCG-induced side effects, if the high-grade fever $\left(>38.5^{\circ} \mathrm{C}\right)$ persists more than 48 hours, a diagnostic evaluation including urine culture, blood tests, and chest $\mathrm{X}$ ray and a consultation with an infectious disease specialist are necessary, along with prompt treatment with more than two antimicrobial agents. While the evaluation is conducted, no further BCG should be given [44].

3.1. Mycotic Aneurysms. The most commonly reported location of mycotic aneurysms after intravesical BCG immunotherapy is aortic (thoracic and abdominal). Moreover, mycotic aneurysms in carotid, iliac, femoral, and popliteal arteries have also been reported. Most reported aneurysms developed within 7-77 months after initial BCG instillation, and more than half of cases presented with rupture of their aneurysms [45]. In a review of 31 aneurysms found in 21 patients after BCG therapy, the most common clinical symptoms were abdominal or back pain $(57 \%)$, general malaise $(52 \%)$, fever $(38 \%)$, and pulsatile or painful mass (19\%) [46]. Psoas abscesses have been reported to occur nearly exclusively in patients with mycotic aneurysms and may be caused by the infected aneurysmal leak [47]. Only a few reported cases have shown evidence of typical caseating granuloma in histopathologic examination, so the definitive diagnosis of mycotic aneurysms is based on culture of the aneurysm specimen [45]. Besides this gold standard, microbiological acid-fast bacilli detection and PCR from various tissue samples have been reported [48]. Treatment of mycotic aneurysms includes anti-TB therapy and vascular surgery. The typical surgical repair entails resection of all infected arterial tissues for large aneurysms and revascularization with in situ biological conduits or extra anatomic bypasses. The use of in situ prosthetic conduits was also reported, but the etiology of these aneurysms was not well defined during the surgical repair [46]. 
TABLE 2: Treatment modality of genitourinary complications induced by intravesical BCG immunotherapy for NMIBC $[13,15,17,20-23,26$, $29,32,38,39]$.

\begin{tabular}{|c|c|c|c|}
\hline $\begin{array}{l}\text { Genitourinary } \\
\text { complications }\end{array}$ & Initial therapy & Auxiliary treatment & BCG adjustment \\
\hline $\begin{array}{l}\text { Cystitis (irritative voiding } \\
\text { symptoms }>48 \text { hours or } \\
\text { intolerable) }\end{array}$ & $\begin{array}{c}\text { Spasmolytics, anticholinergics or } \\
\text { nonsteroidal anti-inflammatory } \\
\text { drugs }\end{array}$ & $\begin{array}{l}\text { Antibiotics administration If } \\
\text { bacterial cystitis is diagnosed }\end{array}$ & $\begin{array}{l}\text { Withheld until symptom relieves } \\
\text { and antibiotic therapy ends }\end{array}$ \\
\hline Bladder contracture & Bladder hydrodistension & $\begin{array}{l}\text { Systemic steroids; } \\
\text { Exceptionally surgery (bladder } \\
\text { augmentation or cystectomy) }\end{array}$ & $\begin{array}{l}\text { Discontinue for decreased bladder } \\
\text { capacity }\end{array}$ \\
\hline Bladder ulceration & $\begin{array}{l}300 \mathrm{mg} \text { isoniazid and } 600 \mathrm{mg} \\
\text { rifampin daily for } 6 \text { months }\end{array}$ & None & $\begin{array}{c}\text { Withheld until resolution of the } \\
\text { bladder lesion and BCG negative } \\
\text { urine }\end{array}$ \\
\hline Granulomatous balanitis & $\begin{array}{l}\text { Various combinations of isoniazid, } \\
\text { ethambutol or rifampin for } 6 \text { to } 12 \\
\text { months }\end{array}$ & None & Withheld until the lesion resolves \\
\hline $\begin{array}{l}\text { Tuberculous } \\
\text { epididymo-orchitis }\end{array}$ & $\begin{array}{l}300 \mathrm{mg} \text { isoniazid and } 600 \mathrm{mg} \\
\text { rifampin daily for } 3 \text { to } 6 \mathrm{months}\end{array}$ & $\begin{array}{c}\text { For isoniazid resistance, } \\
\text { fluoroquinolones or an anti-TB } \\
\text { aminoglycoside; } \\
\text { For lesion refractory to anti-TB } \\
\text { therapy, scrotal exploration and } \\
\text { epididymo-orchiectomy }\end{array}$ & No further BCG \\
\hline Symptomatic prostatitis & $\begin{array}{l}300 \mathrm{mg} \text { isoniazid and } 600 \mathrm{mg} \\
\text { rifampin daily for } 3 \text { to } 6 \text { months }\end{array}$ & $\begin{array}{c}\text { Antibiotics (fluoroquinolones) as } \\
\text { necessary; } \\
\text { Surgical drainage for abscess; } \\
\text { Biopsy if no improvement on } \\
\text { medication }\end{array}$ & No further BCG \\
\hline Ureteral obstruction & $\begin{array}{l}300 \mathrm{mg} \text { isoniazid and } 600 \mathrm{mg} \\
\text { rifampin daily for } 3 \text { to } 6 \text { months }\end{array}$ & $\begin{array}{l}\text { A temporary drainage (ureteral } \\
\text { stenting or percutaneous } \\
\text { nephrostomy) for hydronephrosis } \\
\text { despite conservative therapy }\end{array}$ & $\begin{array}{l}\text { Withheld when onset } \\
\text { hydronephrosis; May resume after } \\
\text { resolution }\end{array}$ \\
\hline Kidney infections & $\begin{array}{c}300 \mathrm{mg} \text { isoniazid, } 600 \mathrm{mg} \text { rifampin } \\
\text { and } 1200 \mathrm{mg} \text { ethambutol daily for } 6 \\
\text { months }\end{array}$ & $\begin{array}{c}\text { Biopsy if no response to medical } \\
\text { treatment }\end{array}$ & No further BCG \\
\hline
\end{tabular}

3.2. Miliary Pulmonary Tuberculosis. Pulmonary complications following intravesical BCG immunotherapy are not common, with an incidence of $0.3 \%-0.7 \%$ of treated patients, presenting as interstitial pneumonitis or miliary dissemination $[8,39]$. Symptom onset of miliary dissemination may be abrupt or subacute, and most patients initially present with fever without apparent focus. In a study enrolling 23 male patients after 4 to 16 BCG instillations, 13 patients presented a variety of untypical symptoms, including fever, chills, and weight loss, in addition to respiratory symptoms like cough and dyspnea [49]. Whenever a suspicion of miliary pulmonary tuberculosis is suspected, a chest CT scan should be performed as chest X-ray imaging may miss up to $25 \%$ of cases [50]. The detection of acid-fast bacilli positive culture and positive PCR test from sputum or bronchoalveolar lavage can confirm the diagnosis. Considering the fact that $5.4 \%$ attributable mortality was observed by a review of the literature [8], it is essential to establish a prompt diagnosis and to initiate anti-TB therapy without delay. Instead of a standardized protocol, a variety of combined isoniazid, ethambutol, streptomycin, or rifampin for 6 to 12 months can provide effective treatment for miliary pulmonary tuberculosis induced by BCG therapy.
3.3. Granulomatous Hepatitis. Hepatic complication, typically granulomatous hepatitis, is a rare but fatal complication after intravesical BCG immunotherapy $[6,8]$. Granulomatous hepatitis can develop within hours to months or longer following intravesical BCG therapy and present with symptoms and signs of hepatitis, including fever, anorexia, and jaundice [51]. Whereas the diagnosis may be established through detection of acid-fast bacilli in patient's serum or liver tissue by staining techniques, the best differential diagnosis is histopathologic lobular hepatitis by liver biopsy. Initial antiTB treatment is essential, and the recommended regimen consists of $300 \mathrm{mg}$ isoniazid, $600 \mathrm{mg}$ rifampin, and $1200 \mathrm{mg}$ ethambutol daily for 6 months.

3.4. Reactive Arthritis. Osteoarticular complications associated with intravesical BCG therapy are uncommon [52]. Although the mechanisms of rheumatic adverse events of BCG immunotherapy remain not fully clarified, the reactive arthritis is most likely invoked by a systemic immunemediated response generated by repeated stimuli with live attenuated strains of $M$. bovis and their antigens spreading from the bladder to the circulation [53]. In a systematic review of 89 patients of reactive arthritis following BCG 
instillation, the symptom of reactive arthritis appeared after a mean number of instillations of 5.8, 13.5 days on average from the last instillation [54]. According to the prevalence, the more frequently affected joints were knee (84.3\%), ankle (55.1\%), hand (39.3\%), wrist (32.6\%), and foot (28.1\%), and polyarthritis is the most common clinical feature (55.1\%) of reactive arthritis related to BCG immunotherapy. Only $20.2 \%$ of the patients presented with warning symptoms, including fever, urinary symptoms, unspecific arthralgias, and myalgias. Although the inflammatory joint involvement is induced by an autoimmune reaction, synovial fluid analysis is required to rule out septic arthritis. Therapeutic strategies for BCG reactive arthritis are not well established in the literatures, but the outcome was reported favourable, with no recurrence under nonsteroidal anti-inflammatory drugs, in association with corticosteroids suggested by some authors, and after discontinuation of BCG therapy. For severe cases or those without response to initial therapy, disease-modifying antirheumatic drugs (methotrexate) could be indicated, and addition of isoniazid has also been proposed [55].

3.5. Tuberculous Spondylitis. Osteitis is rare secondary to BCG immunization, occurring in less than 37 per 100,000 cases [56]. Updated to 2018, only 23 cases of tuberculous spondylitis or vertebral osteomyelitis following intravesical BCG were reported in the English literature [57]. All these patients were male, with a mean age of 73.2 (3594) years and with a median interval of 1.3 years (0.5 months-12 years) between BCG instillation and the onset of spondylitis. Chronic back pain was the most common complaint, and serious neurological symptoms might occur as a result of neurosurgical spinal cord decompression [58]. BCG spondylitis is thought to develop by hematogenous spread from the deep pelvic veins to the internal vertebral venous plexuses, which may explain its high incidence in the thoracolumbar spine [59]. The growth of Mycobacterium in culture specimens obtained from the infected tissue is the most confirmatory diagnostic test of tuberculous spondylitis; however, histopathological granulomas and acid fast bacilli stain are considered as reference standards for all other diagnostic modalities [60]. Without standard protocol for managing tuberculous spondylitis or vertebral osteomyelitis, most patients were treated by multidrug anti-TB therapy (isoniazid, rifampin, and ethambutol) for an average of 12 months (9-15 months). Surgical intervention will be necessary when the patient has further complications, including spinal cord injury, spinal instability, and abscess formation.

3.6. BCG Sepsis. Although a life-threatening septic reaction occurs in an estimated incidence of approximately 1 of 15,000 patients treated with intravesical BCG immunotherapy [39], systemic BCG infection should be suspected in any patient who presents with persistent fever after BCG instillation. Characterized by chills, fever, and hypotension with potential progression to multisystem organ failure, this most dangerous complication is a result of either systemic mycobacterial sepsis and/or a systemic hypersensitivity reaction to BCG [42]. Recommended anti-TB treatment for BCG sepsis consists of $300 \mathrm{mg}$ isoniazid, $600 \mathrm{mg}$ rifampin, and $1200 \mathrm{mg}$ ethambutol daily for 3 to 6 months. In addition, steroid treatment of $40 \mathrm{mg}$ prednisolone should be given intravenously from the beginning of therapy and be tapered gradually after the sepsis is controlled [11]. The treatment modality of systemic complications induced by intravesical BCG immunotherapy was listed in Table 3.

3.7. Rare Complications. Central nervous system infections caused by $M$. bovis are very rare; only two cases of cerebellar tuberculomas were reported caused by $M$. bovis BCG in immunocompetent patients without any evidence of systemic dissemination after intravesical BCG immunotherapy [61, 62]. Both cases occurred in elderly male patients with neurological symptoms and signs. Magnetic resonance imaging or contrasted CT scan revealed cerebral nodular foci or mass effect. Although the pathological diagnosis showed chronic granulomatous inflammation from a stereotactic biopsy, the acid-fast smear of the tissue sample was negative. Both patients had a successful response to a 12-month anti-TB medication. In addition, one case used a concomitant steroid therapy, which included dexamethasone transitioned to a 3-month prednisone taper.

There are 15 cases of ocular inflammation after intravesical BCG instillations in the literature. Although crossreactivity and immunologic reactions are possibly implicated in uveitis after BCG instillations, culture-positive M. bovis endophthalmitis was reported in 4 cases which confirmed a direct vitreous invasion after hematogenous dissemination of the microorganism [63]. These cases highlighted a poor ocular outcome despite of an adequate systemic anti-TB therapy, and intravitreal therapy targeted toward M. bovis or additional therapy may be required.

Haemophagocytic syndrome is a very rare but potentially fatal complication of intravesical BCG immunotherapy. This challenging syndrome consists of a sepsis-like state together with variable cytopenia, hepatosplenomegaly, coagulation disorders, and lymphadenopathy; eventually multiple organ failure ensues with a high mortality rate [64]. Early diagnosis is essential to initiate appropriate treatment and improve the survival and quality of life. The immediate aim of therapy is suppression of the increased immune response and specific treatment of the underlying disease [65]. Immunomodulatory regimen depends on the severity of the conditions, including corticosteroids, intravenous immunoglobulins, cyclosporine A, etoposide, antithymocyte globulin, plasma exchange, and splenectomy. Water-soluble steroids such as dexamethasone or methylprednisolone are preferred because of their permeability through blood brain barrier.

\section{Predisposing Factors Endorsing Complications}

4.1. Immunosuppression. The incidence of BCG induced adverse events in immunosuppressed patients is unclear because of paucity of data in the literature. In the largest 
TABLE 3: Treatment modality of systemic complications induced by intravesical BCG immunotherapy for NMIBC $[8,11,43,44,46,51,54,55$, 57].

\begin{tabular}{|c|c|c|c|}
\hline Systemic complications & Initial therapy & Auxiliary treatment & BCG adjustment \\
\hline $\begin{array}{l}\text { Fever }\left(>38.5^{\circ} \mathrm{C} \text { for more than } 48\right. \\
\text { hours) }\end{array}$ & $\begin{array}{l}300 \mathrm{mg} \text { isoniazid, } 600 \mathrm{mg} \text { rifampin, } \\
\text { and } 1200 \mathrm{mg} \text { ethambutol daily for at } \\
\text { least } 3 \text { months. } \\
\text { Plus an empirical non-specific } \\
\text { antibiotic to cover Gram-negative } \\
\text { bacteria and/or Enterococcus with or } \\
\text { without steroids. }\end{array}$ & $\begin{array}{l}\text { Treatment adapted to urine culture } \\
\text { results. }\end{array}$ & No further BCG \\
\hline Mycotic Aneurysms & $\begin{array}{c}300 \mathrm{mg} \text { isoniazid, } 600 \mathrm{mg} \text { rifampin } \\
\text { and } 1200 \mathrm{mg} \text { ethambutol daily for } 12 \\
\text { months }\end{array}$ & $\begin{array}{l}\text { Surgical resection of aneurysms and } \\
\text { revascularization (eg extra anatomic } \\
\text { bypass or in situ replacement) }\end{array}$ & No further BCG \\
\hline Miliary pulmonary tuberculosis & $\begin{array}{l}\text { A variety of combined isoniazid, } \\
\text { ethambutol, streptomycin, or } \\
\text { rifampin for } 6 \text { to } 12 \text { months }\end{array}$ & None & No further BCG \\
\hline Granulomatous hepatitis & $\begin{array}{c}300 \mathrm{mg} \text { isoniazid, } 600 \mathrm{mg} \text { rifampin } \\
\text { and } 1200 \mathrm{mg} \text { ethambutol daily for } 6 \\
\text { months }\end{array}$ & None & No further BCG \\
\hline Reactive arthritis & $\begin{array}{l}\text { Non-steroidal anti-inflammatory } \\
\text { drugs } \\
\pm \text { corticosteroids }\end{array}$ & $\begin{array}{c}\text { Disease-modifying antirheumatic } \\
\text { drugs (methotrexate) and/or } \\
\text { isoniazid for severe or unimproved } \\
\text { cases }\end{array}$ & $\begin{array}{l}\text { BCG can be resumed after } \\
\text { benefit-risk assessment till } \\
\text { resolution of symptoms; } \\
\text { Dose reduction should be } \\
\text { considered }\end{array}$ \\
\hline Tuberculous Spondylitis & $\begin{array}{l}\text { Combined isoniazid, rifampin and } \\
\text { ethambutol for } 9 \text { to } 12 \text { months }\end{array}$ & $\begin{array}{l}\text { Surgical intervention for further } \\
\text { complications }\end{array}$ & No further BCG \\
\hline BCG sepsis & $\begin{array}{l}\text { Emergency admission and intensive } \\
\text { care; } \\
300 \mathrm{mg} \text { isoniazid, } 600 \mathrm{mg} \text { rifampin } \\
\text { and } 1200 \mathrm{mg} \text { ethambutol daily for } 3 \\
\text { to } 6 \text { months; } \\
\text { Intravenous } 40 \mathrm{mg} \text { prednisolone } \\
\text { should be given initially and oral } \\
\text { steroids taper gradually }\end{array}$ & $\begin{array}{c}\text { Broad-spectrum antibiotics as } \\
\text { needed }\end{array}$ & No further BCG \\
\hline
\end{tabular}

case series of 45 immunosuppressed patients (12 with solid organ transplants, 23 receiving systemic chemotherapy for unrelated cancer, and 10 on steroids for autoimmune disease) treated with intravesical BCG for bladder cancer, BCG therapy was found well-tolerated, and no BCG sepsis was reported [66]. In the literature, only one case of disseminated BCG-induced sepsis was reported 7 years after a 6-week induction course of intravesical BCG therapy for high-grade noninvasive papillary urothelial carcinoma and 1.5 years following immunosuppression for a renal transplantation [67]. Given the fact that this patient's urine and blood mycobacterial culture was positive for the strain of intravesical BCG, the sepsis was most likely caused by organism spreading in the setting of immunosuppression therapy for transplant, rather than systemic hypersensitivity reaction. Therefore, EAU guideline suggests that BCG should be used with caution in immunocompromised patients, despite the comparable incidences of BCG-induced complications reported between patients with and without immunocompromised status [44]. Although BCG is not recommended as vaccination in patients with autoimmune inflammatory rheumatic diseases [68], there is little literature to prove that the safety of intravesical BCG immunotherapy is compromised by administration of synthetic or biological disease-modifying antirheumatic drugs [69].

4.2. Geriatric Patients. In the treatment for geriatric patients, age-related deterioration of innate and adaptive immunities and declines in performance status may influence the therapeutic toxicity risk. For elderly patients, the potential side effects and complications of intravesical BCG immunotherapy may be more problematic and not well tolerated. In a study of series of 58 patients, a nearly three-fold higher rate of complications was found in patients older than 70 years compared to younger patients $(48.6 \%$ vs. $17.6 \%$, respectively) following maintenance BCG therapy [70]. In a recent retrospective study on 200 patients older than 80 years, the elderly patients with multiple comorbidities received a tailored regimen of BCG administration with biweekly scheme, which maintained optimal oncological responses with a significantly lower rate of complications (15\% vs. $27 \%$ ) than that in the elderly patients with better conditions under standard weekly BCG therapy [71].

4.3. Chronic Comorbidities. Although chronic comorbidities were regarded as potential predisposing factors of increasing 
the risk of systemic side effects [42], there was no difference in the incidence of chronic comorbidities such as hypertension, diabetes mellitus, renal insufficiency, and liver disease between 11 patients with BCG infection and 245 others without BCG infection in a review of adjunctive BCG therapy for bladder cancer [8]. In a recent investigation on the influence to intravesical BCG immunotherapy from metabolic syndrome, defined as having three of four components: diabetes mellitus, hyperlipidemia, hypertension, or body mass index $\geq 30 \mathrm{~kg} / \mathrm{m}^{2}$, there was no significant association between metabolic syndrome and the type of BCG failure consisting of recurrence, progression, or intolerance of therapy [72].

\section{Prevention}

Adjunctive BCG administration is imperatively initiated a minimum of 2 weeks after TUR to allow for adequate healing of the urothelium and to prevent systemic absorption of this agent. Moreover, intravesical BCG instillation is contraindicated in patients with visible hematuria, after traumatic catheterization, or with symptomatic urinary tract infection [44]. The potential effect of some antibiotics, notably the fluoroquinolones on BCG viability, and consequent effectiveness should be taken into account.

Reduced dose of intravesical BCG has been reported helpful to decrease the potential toxicity of BCG. In a randomized prospective study, the percentage of no local toxicity in 248 patients with reduced dose of $27 \mathrm{mg}$ intravesical BCG was significantly lower than that in 252 patients with standard dose of $81 \mathrm{mg}$ (33.3\% vs. $45.3 \%)$ with similar outcomes for recurrence and progression, but the differences in severe systemic toxicity were not significant between reduced dose arm (4.4\%) and standard dose arm (3.6\%) [73]. However, in a more recent study of 1316 patients, one-third dose was compared to a full dose of BCG given for 1 year or 3 years, and no significant differences in side effects were detected according to dose or duration of BCG treatment in the four arms [11].

Prophylactic medication has been used effectively to decrease the potential toxicity of intravesical BCG. In a randomized prospective, double-blind, multicentre study of 120 patients who received 6 weekly instillations of BCG for urothelial cancer, local side-effects confined to the bladder were significantly lower among those with a 3-day course of isoniazid $300 \mathrm{mg}$ than with placebo (35\% vs. $48 \%$ ) [74]. On the contrary, in a subsequent larger randomized trial, the incidence of cystitis, frequency, hematuria, or severe fever was not reduced significantly in patients treated with BCG and isoniazid, and one case of BCG-induced lung infection developed in this group. Preventive isoniazid therapy also led to treatment discontinuation in significantly more patients (13\% vs. 7\%) [75]. Beside this, prophylactic 3-day course of prulifloxacin $600 \mathrm{mg}$ was reported to have a significant effect to prevent overall, moderate, and severe adverse events after the fourth intravesical BCG instillation for intermediateor high-risk NMIBC in a prospective, randomized openlabel controlled clinical trial [76]. In addition, a lower proportion that stopped or delayed the full induction course of BCG instillations was noted in patients treated by prior prulifloxacin than in those without prophylactic medication $(19 \%$ vs. $34 \%)$, and the recurrence rates at 3-month or 6-month postoperative cystoscopy were not affected by prulifloxacin treatment. Similarly, in a randomized, prospective, double-blind, placebo controlled, multicenter study, ofloxacin significantly decreased by $18.5 \%$ the incidence of moderate and severe adverse events associated with BCG intravesical therapy, particularly class III events, which are primarily associated with patient dropout [15].

\section{Conclusions}

Intravesical BCG immunotherapy has been proved to be effective in the prevention of recurrence and progression of NMIBC for over 40 years; its use is still problematic due to a diverse array of complications that may develop within days to years following the initiation of BCG instillation. Despite these severe complications being uncommon, every physician faced with a patient who has a history of intravesical BCG therapy should be aware of the potential adverse events and the management. Considering the fact that BCG infections and reactions can occur at any organ or position in the body, a detailed medical history provides important clinical value. Because acid-fast staining, culture, and PCR testing are not always positive, tissue biopsies should be performed to evaluate histopathological formation and presence of $M$. bovis. Whereas the most common side effects are self-limited, anti-TB therapy must be used as soon as the diagnosis is established to avert more severe downstream complications. Multidrug anti-TB therapy for 3-12 months may be required along with the rare use of surgery.

\section{Conflicts of Interest}

The authors declare that there are no conflicts of interest regarding the publication of this paper.

\section{References}

[1] J. Ferlay, I. Soerjomataram, R. Dikshit et al., "Cancer incidence and mortality worldwide: sources, methods and major patterns in GLOBOCAN 2012," International Journal of Cancer, vol. 136, no. 5, pp. E359-E386, 2014.

[2] M. Unda-Urzaiz, J. Cozar-Olmos, B. Miñana-Lopez et al., "Eficacia y seguridad de distintas cepas de BCG en el tratamiento del tumor vesical en práctica clínica habitual," Actas Urológicas Españolas, vol. 42, no. 4, pp. 238-248, 2018.

[3] R. F. Han and J. G. Pan, "Can intravesical bacillus CalmetteGuérin reduce recurrence in patients with superficial bladder cancer? A meta-analysis of randomized trials," Urology, vol. 67, no. 6, pp. 1216-1223, 2006.

[4] M. D. Shelley, M. D. Mason, and H. Kynaston, "Intravesical therapy for superficial bladder cancer: A systematic review of randomised trials and meta-analyses," Cancer Treatment Reviews, vol. 36, no. 3, pp. 195-205, 2010.

[5] J. A. Witjes, J. Palou, M. Soloway et al., "Current clinical practice gaps in the treatment of intermediate- and high-risk non-muscle-invasive bladder cancer (NMIBC) with emphasis on the use of bacillus Calmette-Guérin (BCG): Results of 
an international individual patient data survey (IPDS)," $B J U$ International, vol. 112, no. 6, pp. 742-750, 2013.

[6] D. L. Lamm, B. A. Blumenstein, J. D. Crissman et al., "Maintenance bacillus Calmette-Guerin immunotherapy for recurrent $\mathrm{Ta}, \mathrm{T} 1$ and carcinoma in situ transitional cell carcinoma of the bladder: a randomized southwest oncology group study," The Journal of Urology, vol. 163, no. 4, pp. 1124-1129, 2000.

[7] R. J. Sylvester, M. A. Brausi, W. J. Kirkels et al., "Long-term efficacy results of EORTC genito-urinary group randomized phase 3 study 30911 comparing intravesical instillations of epirubicin, bacillus calmette-guérin, and bacillus calmetteguérin plus isoniazid in patients with intermediate- and highrisk stage Ta T1 urothelial carcinoma of the bladder," European Urology, vol. 57, no. 5, pp. 766-773, 2010.

[8] M. A. P.-J. Asín, M. Fernández-Ruiz, F. López-Medrano et al., "Bacillus Calmette-Guérin (BCG) infection following intravesical BCG administration as adjunctive therapy for bladder cancer: incidence, risk factors, and outcome in a single-institution series and review of the literature," Medicine, vol. 93, no. 17, pp. 236-254, 2014.

[9] G. Redelman-Sidi, M. S. Glickman, and B. H. Bochner, “The mechanism of action of BCG therapy for bladder cancer-a current perspective," Nature Reviews Urology, vol. 11, no. 3, pp. 153-162, 2014.

[10] M. P. Bilsen, K. E. van Meijgaarden, H. K. de Jong et al., "A novel view on the pathogenesis of complications after intravesical BCG for bladder cancer," International Journal of Infectious Diseases, vol. 72, pp. 63-68, 2018.

[11] M. Brausi, J. Oddens, R. Sylvester et al., "Side effects of bacillus calmette-guérin (BCG) in the treatment of intermediate- and high-risk Ta, T1 papillary carcinoma of the bladder: results of the EORTC genito-urinary cancers group randomised phase 3 study comparing one-third dose with full dose and 1 year with 3 years of maintenance BCG," European Urology, vol. 65, no. 1, pp. 69-76, 2014.

[12] L. C. Macleod, T. C. Ngo, and M. L. Gonzalgo, "Complications of Intravesical Bacillus Calmette-Guérin," Canadian Tax Journal, vol. 8, no. 7-8, pp. E540-E544, 2014.

[13] M. P. Koya, M. A. Simon, and M. S. Soloway, "Complications of intravesical therapy for urothelial cancer of the bladder," The Journal of Urology, vol. 175, no. 6, pp. 2004-2010, 2006.

[14] M. H. Johnson, K. G. Nepple, V. Peck et al., "Randomized controlled trial of oxybutynin extended release versus placebo for urinary symptoms during intravesical bacillus calmetteguérin treatment," The Journal of Urology, vol. 189, no. 4, pp. 1268-1274, 2013.

[15] M. Colombel, F. Saint, D. Chopin, B. Malavaud, L. Nicolas, and P. Rischmann, "The effect of ofloxacin on bacillus calmetteguerin induced toxicity in patients with superficial bladder cancer: results of a randomized, prospective, double-blind, placebo controlled, multicenter study," The Journal of Urology, vol. 176, no. 3, pp. 935-939, 2006.

[16] K. Decaestecker and W. Oosterlinck, "Managing the adverse events of intravesical bacillus Calmette-Guérin therapy," Research and Reports in Urology, no. 7, pp. 157-163, 2015.

[17] C. Garcia, H. Jina, P. Bergersen, and V. Chalasani, "Bladder contracture - a rare and serious side effect of intravesical bacillus calmette-guérin therapy," Urology Case Reports, vol. 4, pp. 22-24, 2016.

[18] A. M. Nieder, P. D. Sved, J. P. Stein, D. G. Skinner, and M. S. Soloway, "Cystoprostatectomy and orthotopic ileal neobladder reconstruction for management of bacille Calmette Guérininduced bladder contractures," Urology, vol. 65, no. 5, pp. 909912, 2005.

[19] J. A. Witjes, J. Palou, M. Soloway et al., "Clinical practice recommendations for the prevention and management of intravesical therapy-associated adverse events," European Urology Supplements, vol. 7, no. 10, pp. 667-674, 2008.

[20] K. Numakura, N. Tsuchiya, H. Tsuruta et al., "Efficacy and safety of bladder hydrodistension for decreased bladder capacity induced by intravesical BCG therapy," Scandinavian Journal of Urology, vol. 50, no. 6, pp. 429-432, 2016.

[21] R. Wittes, L. Klotz, and U. Kosecka, "Severe bacillus CalmetteGuerin cystitis responds to systemic steroids when antituberculous drugs and local steroids fail," The Journal of Urology, vol. 161, no. 5, pp. 1568-1569, 1999.

[22] J. E. Vetorazzo Filho, L. A. Bahia, B. C. Vedovato et al., "Cistectomia com reconstrução de neobexiga ortotópica ileal para tratamento de bexiga contraída após aplicação de bacilo de Calmette-Guérin intravesical," Einstein (São Paulo), vol. 12, no. 4, pp. 502-504, 2014.

[23] V. Ströck, L. Dotevall, T. Sandberg, C. K. Gustafsson, and S. Holmäng, "Late bacille Calmette-Guérin infection with a large focal urinary bladder ulceration as a complication of bladder cancer treatment," BJU International, vol. 107, no. 10, pp. $1592-$ 1597, 2011.

[24] G. Aslan, C. Sevinc, B. Tuna, S. Ozkal, and K. Yorukoglu, "Penile lesion with inguinal adenopathy after intravesical Bacillus Calmette-Guerin instillation therapy," Indian Journal of Urology, vol. 29, no. 1, pp. 70-72, 2013.

[25] S. I. A. Lestre, C. D. Gameiro, A. João, and M. J. P. Lopes, "Granulomas of the penis - A rare complication of intravesical therapy with Bacillus Calmette-Guerin," Anais Brasileiros de Dermatologia, vol. 86, no. 4, pp. 759-762, 2011.

[26] V. Sharma, P. Sethy, P. Dogra, U. Singh, and P. Das, "Primary tuberculosis of glans penis after intravesical bacillus calmette guerin immunotherapy," Indian Journal of Dermatology, Venereology and Leprology, vol. 77, no. 1, pp. 47-50, 2011.

[27] C. Colomba, P. Di Carlo, G. Guadagnino et al., "A Case of Epididymo-orchitis after intravesical bacille Calmette-Guérin therapy for superficial bladder carcinoma in a patient with latent tuberculosis infection," Infectious Agents and Cancer, vol. 11, no. 1, article 25, 2016.

[28] R. Salvador, R. Vilana, X. Bargalló, X. Araque, and C. Nicolau, "Tuberculous epididymo-orchitis after intravesical BCG therapy for superficial bladder carcinoma: Sonographic findings," Journal of Ultrasound in Medicine, vol. 26, no. 5, pp. 671-674, 2007.

[29] V. Demers and V. Pelsser, “BCGitis': a rare case of tuberculous epididymo-orchitis following intravesical bacillus CalmetteGuerin therapy," Journal of Radiology Case Reports, vol. 6, no. 11, pp. 16-21, 2012.

[30] I. El Hamrouni, T. Puttemans, E. Dardenne, and A. Draguet, "Unusual Case of Testicular Tuberculosis," Journal of the Belgian Society of Radiology, vol. 101, no. 1, article 17, pp. 1-4, 2017.

[31] H. Harada, M. Seki, H. Shinojima, M. Miura, T. Hirano, and M. Togashi, "Epididymo-orchitis caused by intravesically instillated bacillus Calmette-Guérin: Genetically proven using a multiplex polymerase chain reaction method," International Journal of Urology, vol. 13, no. 2, pp. 183-185, 2006. 
[32] M. R. Watts, P. C. Taylor, V. Sintchenko et al., "Implications of isoniazid resistance in mycobacterium bovis bacillus calmetteguerin used for immunotherapy in bladder cancer," Clinical Infectious Diseases, vol. 52, no. 1, pp. 86-88, 2011.

[33] M. Balasar, M. Doğan, A. Kandemir et al., "Investigation of granulomatous prostatitis incidence following intravesical BCG therapy," International Journal of Clinical and Experimental Medicine, vol. 7, no. 6, pp. 1554-1557, 2014.

[34] P. A. Humphrey, "BCG Prostatitis," The Journal of Urology, vol. 188, no. 3, pp. 961-962, 2012.

[35] M. Matsushima, E. Kikuchi, H. Akita, A. Miyajima, M. Oya, and M. Jinzaki, "Natural course of asymptomatic abnormal prostate findings incidentally detected by CT after intravesical BCG therapy," International Journal of Clinical Oncology, vol. 22, no. 3, pp. 554-562, 2017.

[36] S. Rais-Bahrami, J. W. Nix, B. Turkbey et al., "Clinical and multiparametric MRI signatures of granulomatous prostatitis," Abdominal Radiology, vol. 42, no. 7, pp. 1956-1962, 2017.

[37] V. Serretta, C. S. Gesolfo, F. Di Maida et al., "The clinical value of PSA increase during intravesical adjuvant therapy for nonmuscle-invasive bladder cancer," Urologia Journal, vol. 83, no. 3, pp. 145-148, 2016.

[38] T. R. Aust and J. A. Massey, "Tubercular prostatic abscess as a complication of intravesical bacillus Calmette-Guérin immunotherapy," International Journal of Urology, vol. 12, no. 10, pp. 920-921, 2005.

[39] D. L. Lamm, "Efficacy and safety of bacille Calmette-Guérin immunotherapy in superficial bladder cancer," Clinical Infectious Diseases, vol. 31, supplement 3, pp. S86-S90, 2000.

[40] T. Kaneko, K. Fujita, and Y. Homma, "Transient anuria requiring nephrostomy after intravesical bacillus Calmette-Guérin instillations for superficial bladder cancer," International Journal of Urology, vol. 13, no. 3, pp. 294-295, 2006.

[41] T. Al-Qaoud, F. Brimo, A. G. Aprikian, and S. Andonian, "BCGrelated renal granulomas managed conservatively: a case series," Canadian Tax Journal, vol. 9, no. 3-4, pp. E200-E203, 2015.

[42] F. Liaw, Y. Y. Tan, and D. Hendry, "Systemic BCG-osis following intravesical BCG instillation for bladder carcinoma," Clinical Case Reports, vol. 5, no. 10, pp. 1569-1572, 2017.

[43] P. Rischmann, F. Desgrandchamps, B. Malavaud, and D. K. Chopin, "BCG intravesical instillations: Recommendations for side-effects management," European Urology, vol. 37, no. 1, pp. 33-36, 2000.

[44] M. Babjuk, M. Burger, E. Compérat et al., EAU Non-muscleinvasive Bladder Cancer Guidelines, EAU Guidelines Office, Arnhem, The Netherlands, 2018, https://uroweb.org/guideline/ non-muscle-invasive-bladder-cancer/.

[45] E. Leo, A. L. Molinari, G. Rossi, S. A. Ferrari, A. Terzi, and G. Lorenzi, "Mycotic abdominal aortic aneurysm after adjuvant therapy with bacillus calmette-guérin in patients with urothelial bladder cancer: a rare but misinterpreted complication," Annals of Vascular Surgery, vol. 29, no. 6, pp. 1318.el-1318.e6, 2015.

[46] R. Coscas, J. Arlet, D. Belhomme, J. Fabiani, and J. Pouchot, "Multiple mycotic aneurysms due to Mycobacterium bovis after intravesical bacillus Calmette-Guérin therapy," Journal of Vascular Surgery, vol. 50, no. 5, pp. 1185-1190, 2009.

[47] M. Leeman, P. Burgers, V. Brehm, and J. P. van Brussel, "Psoas abscess after bacille Calmette-Guérin instillations causing iliac artery contained rupture," Journal of Vascular Surgery, vol. 66, no. 4, pp. 1236-1238, 2017.
[48] C. J. Lee, D. Davila, A. Dua et al., "Disseminated mycotic aneurysms following intravesical bacillus calmette-guérin therapy for bladder cancer: case discussion and systematic treatment algorithm," Annals of Vascular Surgery, vol. 39, pp. 284.e5284.e10, 2017.

[49] J. D. Colmenero, R. Sanjuan-Jimenez, B. Ramos, and P. Morata, "Miliary pulmonary tuberculosis following intravesical BCG therapy: case report and literature review," Diagnostic Microbiology and Infectious Disease, vol. 74, no. 1, pp. 70-72, 2012.

[50] G. Calleris, G. Marra, S. Corcione et al., "Miliary pulmonary infection after BCG intravesical instillation: A rare, misdiagnosed and mistreated complication," Le Infezioni in Medicina, vol. 25, no. 4, pp. 366-370, 2017.

[51] M. Moussa and M. Abou Chakra, "Granulomatous hepatitis caused by Bacillus Calmette-Guerin (BCG) infection after BCG bladder instillation: A case report," Urology Case Reports, vol. 20, pp. 3-4, 2018.

[52] S. Miranda, M. Vernet, F. Héron, O. Vittecoq, H. Levesque, and I. Marie, "Arthrites réactionnelles secondaires à la BCGthérapie. Deux observations et revue de la littérature," La Revue de Médecine Interne, vol. 31, no. 8, pp. 558-561, 2010.

[53] E. Tinazzi, V. Ficarra, S. Simeoni, W. Artibani, and C. Lunardi, "Reactive arthritis following BCG immunotherapy for urinary bladder carcinoma: A systematic review," Rheumatology International, vol. 26, no. 6, pp. 481-488, 2006.

[54] L. Bernini, C. U. Manzini, D. Giuggioli, M. Sebastiani, and C. Ferri, "Reactive arthritis induced by intravesical BCG therapy for bladder cancer: our clinical experience and systematic review of the literature," Autoimmunity Reviews, vol. 12, no. 12, pp. 1150-1159, 2013.

[55] R. Ikeuchi, T. Sunada, T. Yoshikawa et al., "Reactive arthritis during the second course of intravesical BCG therapy requiring administration of methotrexate: a case report," Hinyokika Kiyo, vol. 63, no. 8, pp. 329-332, 2017.

[56] C. E, S. M. Mackel, T. Huhta, R. Riesenburger, and S. J. Weller, "Mycobacterial osteomyelitis of the spine following intravesical BCG therapy for bladder cancer," Cureus, vol. 8, no. 3, Article ID e545, 2016.

[57] T. Kusakabe, K. Endo, I. Nakamura et al., "Bacille CalmetteGuérin (BCG) spondylitis with adjacent mycotic aortic aneurysm after intravesical BCG therapy: a case report and literature review," BMC Infectious Diseases, vol. 18, no. 1, p. 290, 2018.

[58] J. Białecki, M. Nowak-Misiak, K. Rąpała, W. Marczyński, G. Suchodolski, and A. Truszczyńska, "Spinal tuberculosis with severe neurological symptoms as a complication of intravesical BCG therapy for carcinoma of the bladder," Neurologia $i$ Neurochirurgia Polska, vol. 50, no. 2, pp. 131-138, 2016.

[59] D. Shedid, S. Obaid, R. Rahme, A. Weil, and C. Gendron, "Mycobacterium bovis spondylodiscitis after intravesical Bacillus Calmette-Guérin therapy," Surgical Neurology International, vol. 2, no. 1, p. 162, 2011.

[60] S. Rajasekaran, D. C. Soundararajan, A. P. Shetty, and R. M. Kanna, "Spinal tuberculosis: current concepts," Global Spine Journal, vol. 8, supplement 4, pp. 96S-108S, 2018.

[61] V. Golub, P. Malhotra, and S. Patel, "Mycobacterial brain tuberculomas due to Bacille Calmette-Guérin intravesical chemotherapy for bladder cancer: A case report and literature review," Canadian Journal of Infectious Diseases \& Medical Microbiology, vol. 22, no. 3, pp. 104-106, 2011.

[62] M. W. Sheron, S. L. Holt, and C. W. Ingram, "Mycobacterium bovis cerebellar abscess following treatment with bacillus 
Calmette-Guérin," Journal of Pharmacy Practice, vol. 30, no. 3, pp. 378-380, 2016.

[63] J. Vadboncoeur, S. Olivier, H. Soualhine, A. Labbé, and M. Bélair, "Endophthalmitis in a patient treated with bacillus calmette-guérin immunotherapy," Retinal Cases \& Brief Reports, vol. 12, no. 4, pp. 326-330, 2018.

[64] S. Misra, A. Gupta, A. Symes, and J. Duncan, "Haemophagocytic syndrome after intravesical bacille Calmette-Guérin instillation," Scandinavian Journal of Urology, vol. 48, no. 3, pp. 328-330, 2014.

[65] M. Ramos-Casals, P. Brito-Zerón, A. López-Guillermo, M. A. Khamashta, and X. Bosch, "Adult haemophagocytic syndrome," The Lancet, vol. 383, no. 9927, pp. 1503-1516, 2014.

[66] H. W. Herr and G. Dalbagni, "Intravesical bacille CalmetteGuérin (BCG) in immunologically compromised patients with bladder cancer," BJU International, vol. 111, no. 6, pp. 984-987, 2013.

[67] J. Ziegler, J. Ho, I. W. Gibson et al., "Disseminated Mycobacterium bovis infection post-kidney transplant following remote intravesical BCG therapy for bladder cancer," Transplant Infectious Disease, vol. 20, no. 5, Article ID e12931, 2018.

[68] M. Bijl, N. Agmon-Levin, J. Dayer, E. Israeli, M. Gatto, and Y. Shoenfeld, "Vaccination of patients with auto-immune inflammatory rheumatic diseases requires careful benefit-risk assessment," Autoimmunity Reviews, vol. 11, no. 8, pp. 572-576, 2012.

[69] J. Morel, S. G. Czitrom, A. Mallick, J. Sellam, and J. Sibilia, "Vaccinations in adults with chronic inflammatory joint disease: Immunization schedule and recommendations for patients taking synthetic or biological disease-modifying antirheumatic drugs," Joint Bone Spine, vol. 83, no. 2, pp. 135-141, 2016.

[70] J. G. Heiner and M. K. Terris, "Effect of advanced age on the development of complications from intravesical bacillus Calmette-Guérin therapy," Urologic Oncology: Seminars and Original Investigations, vol. 26, no. 2, pp. 137-140, 2008.

[71] M. Racioppi, L. Di Gianfrancesco, M. Ragonese, G. Palermo, E. Sacco, and P. Bassi, "The challenges of Bacillus of CalmetteGuerin (BCG) therapy for high risk non muscle invasive bladder cancer treatment in older patients," Journal of Geriatric Oncology, vol. 9, no. 5, pp. 507-512, 2018.

[72] A. T. Lenis, K. Asanad, M. Blaibel, N. M. Donin, and K. Chamie, "Association between metabolic syndrome and recurrence of nonmuscle invasive bladder cancer following bacillus calmetteguérin treatment," Urology Practice, vol. 5, no. 2, pp. 132-138, 2018.

[73] J. A. Martínez-Piñeiro, N. Flores, S. Isorna et al., "Longterm follow-up of a randomized prospective trial comparing a standard $81 \mathrm{mg}$ dose of intravesical bacille Calmette-Guérin with a reduced dose of $27 \mathrm{mg}$ in superficial bladder cancer," BJU International, vol. 89, no. 7, pp. 671-680, 2002.

[74] M. Al Khalifa, P. Elfving, W. Månsson et al., "The effect of isoniazid on BCG-induced toxicity in patients with superficial bladder cancer," European Urology, vol. 37, no. 1, pp. 26-30, 2000.

[75] A. P. M. van der Meijden, M. Brausi, and V. Zambon, "Intravesical instillation of epirubicin, bacillus Calmette-Guerin and bacillus Calmette-Guerin plus isoniazid for intermediate and high risk TA, T1 papillary carcinoma of the bladder: a European Organization for Research and Treatment of Cancer GenitoUrinary Group randomized phase III trial," The Journal of Urology, vol. 166, no. 2, pp. 476-481, 2001.
[76] R. Damiano, M. De Sio, G. Quarto et al., "Short-term administration of prulifloxacin in patients with nonmuscle-invasive bladder cancer: an effective option for the prevention of bacillus Calmette-Guérin-induced toxicity?" BJU International, vol. 104, no. 5, pp. 633-639, 2009. 


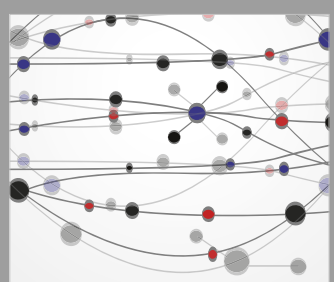

The Scientific World Journal
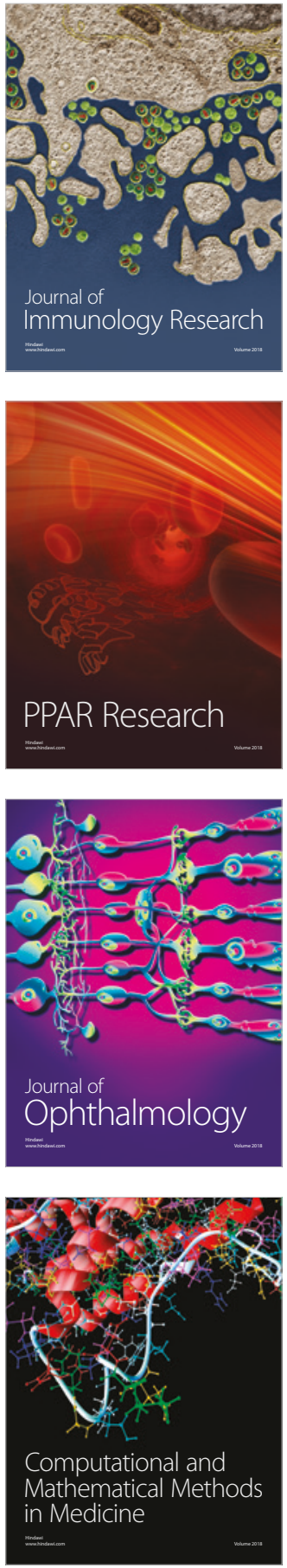

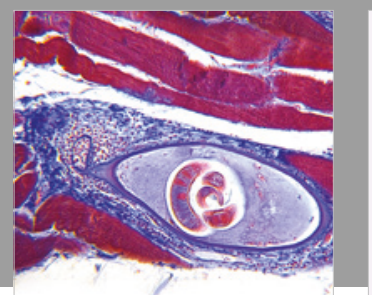

Gastroenterology Research and Practice

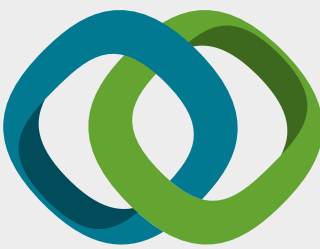

\section{Hindawi}

Submit your manuscripts at

www.hindawi.com
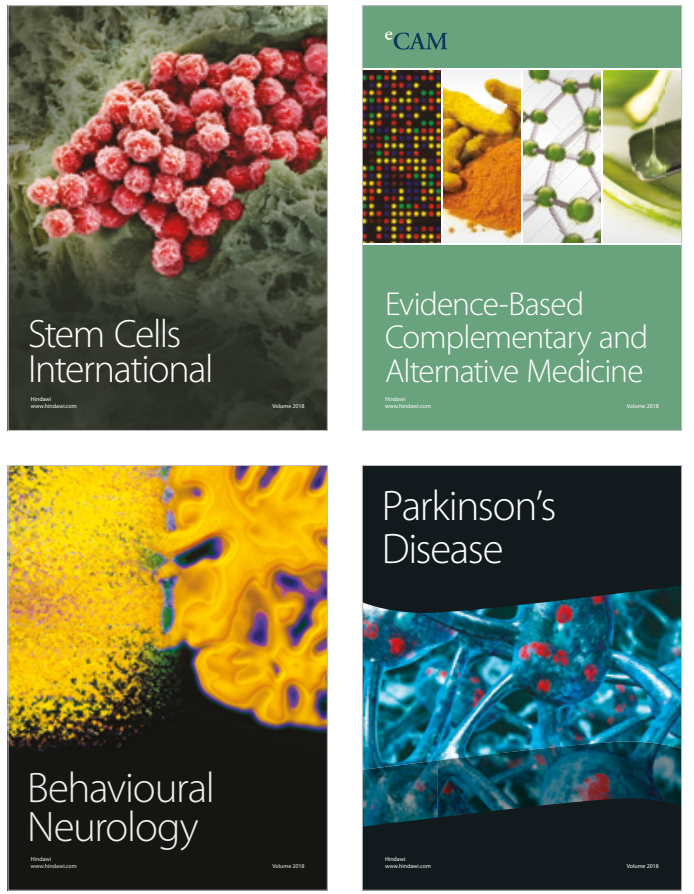

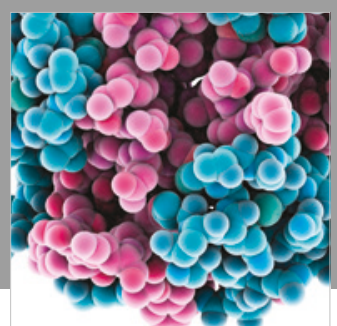

ournal of

Diabetes Research

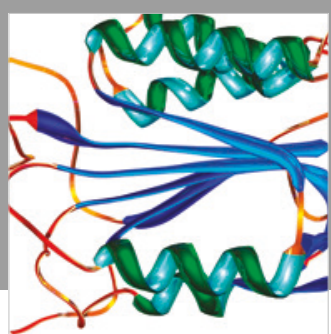

Disease Markers
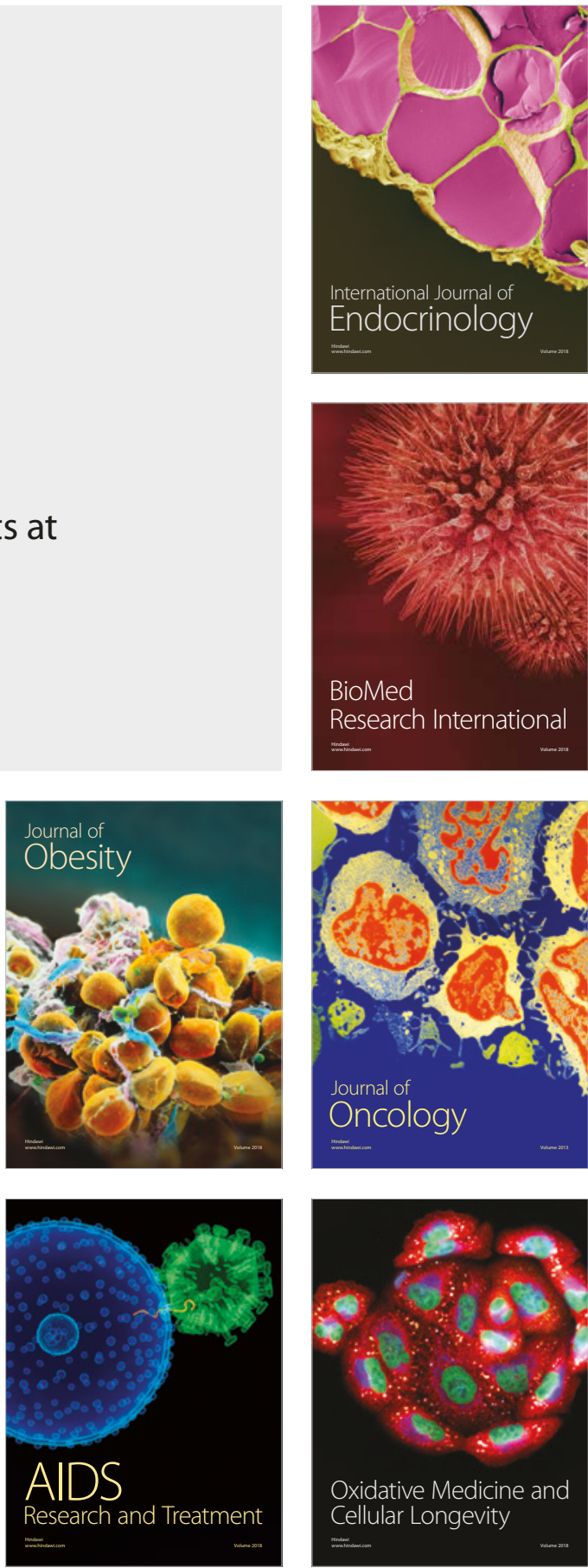